\title{
Relationship between Brazilian airline pilot errors and time of day
}

\author{
M.T. de Mello, A.M. Esteves, M.L.N. Pires, D.C. Santos, L.R.A. Bittencourt, R.S. Silva \\ and S. Tufik
}

Departamento de Psicobiologia, Escola Paulista de Medicina, Universidade Federal de São Paulo, São Paulo, SP, Brasil

Correspondence to: M.T. de Mello, Departamento de Psicobiologia, EPM, UNIFESP, Rua Marselhesa, 535, 04020-060 São Paulo, SP, Brasil

Fax: +55-11-2149-0155. E-mail: tmello@psicobio.epm.br

Flight safety is one of the most important and frequently discussed issues in aviation. Recent accident inquiries have raised questions as to how the work of flight crews is organized and the extent to which these conditions may have been contributing factors to accidents. Fatigue is based on physiologic limitations, which are reflected in performance deficits. The purpose of the present study was to provide an analysis of the periods of the day in which pilots working for a commercial airline presented major errors. Errors made by 515 captains and 472 copilots were analyzed using data from flight operation quality assurance systems. To analyze the times of day (shifts) during which incidents occurred, we divided the light-dark cycle (24:00) in four periods: morning, afternoon, night, and early morning. The differences of risk during the day were reported as the ratio of morning to afternoon, morning to night and morning to early morning error rates. For the purposes of this research, level 3 events alone were taken into account, since these were the most serious in which company operational limits were exceeded or when established procedures were not followed. According to airline flight schedules, $35 \%$ of flights take place in the morning period, $32 \%$ in the afternoon, $26 \%$ at night, and $7 \%$ in the early morning. Data showed that the risk of errors increased by almost $50 \%$ in the early morning relative to the morning period (ratio of 1:1.46). For the period of the afternoon, the ratio was $1: 1.04$ and for the night a ratio of 1:1.05 was found. These results showed that the period of the early morning represented a greater risk of attention problems and fatigue.

Key words: Airline pilot errors; Circadian rhythm

Research supported by Psychopharmacological Research Support Foundation (AFIP), FAPESP (\#98/143033), the Psychobiology and Exercise Research Center (CEPE), and FADA.

Received December 3, 2007. Accepted November 18, 2008

\section{Introduction}

Flight safety is one of the most important and frequently discussed issues in aviation, and in the community in general, since the issue relates to the lives of people and professionals who need to use air transport.

Flight crew shifts result in a desynchronization of circadian rhythm, including oscillations in core body temperature, hormone secretion, sleep, and alertness (1). Airborne crews may present sleepiness because they are working during the circadian cycle low point, corresponding to the lowest body temperatures.
However, there are considerable individual differences in the extent to which fatigue affects performance, physiologic vigilance, and subjective signs of fatigue. These differences include the effects of sleep loss, nighttime work, and considerations of individual sleep needs and recovery times. Differences between individuals may vary depending on age, sleep need, experience, overall state of health, and other factors (2).

There is much interest in determining the relationship between flight crew shifts (schedules) and their association with aviation accidents/incidents caused by fatigue (3), since accident/incident inquiries are crucially impor- 
tant for airline safety. Thus, the purpose of the present study was to provide an analysis of the hours of the day during which pilots working for a Brazilian airline made the most errors.

\section{Material and Methods}

We analyzed records for $155,327 \mathrm{~h}$ flown from April 1 to September 30, 2005 by a Brazilian airline commanded by 515 captains and 472 copilots.

We used the Flight Operations Quality Assurance (FOQA) program to analyze the flight data, which is a safety tool with technology to provide systematic analysis of flight data collected from onboard digital flight data recorders (DFDRs) using the Quick Access Recorder. The aim of the FOQA was to identify the following errors: operational deviations and/or errors, procedural errors and maintenance faults, and the mistakes of procedures always considered human error. All data were validated by pilots of the Flight Safety Department to ensure reliability.

The data collected during the flight were compared to a database with operating limits and maintenance pre-programmed by the manufacturer and/or the operator for each type of aircraft. Parameters for errors were predetermined as values in the program performing the analysis, and the monitoring system is divided into 3 categories: level 1 , value set for operational procedure; level 2, value exceeding operational procedure (company operational procedure); level 3, exceeding company operational value (structural; aircraft manufacturer operational value).

For the purposes of this research, level 3 events alone were taken into account because they were presumed to be the most serious in which operational limits required by the company were exceeded, or when established procedures were not followed.

After members of the FOQA section professional team

Table 1. Ratio of pilot and copilot error as a function of time of day.

\begin{tabular}{lccccc}
\hline Time of day & Clock-hour & $\begin{array}{c}\text { Hours of } \\
\text { flight }(\%)\end{array}$ & $\begin{array}{c}\text { Errors } \\
(\mathrm{N})\end{array}$ & $\begin{array}{c}\text { Errors/100 } \mathrm{h} \\
\text { flight time }\end{array}$ & $\begin{array}{c}\text { Normalized } \\
\text { data }\end{array}$ \\
\hline Morning & $6: 00-11: 59$ & $54,364(35 \%)$ & 352 & 6.47 & 1.00 \\
Afternoon & $12: 00-17: 59$ & $49,705(32 \%)$ & 335 & 6.74 & 1.04 \\
Night & $18: 00-23: 59$ & $40,385(26 \%)$ & 275 & 6.81 & 1.05 \\
Early morning & $0: 00-5: 59$ & $10,873(7 \%)$ & 103 & 9.47 & 1.46 \\
Total & & 155,327 & 1065 & 6.86 & 1.06 \\
\hline
\end{tabular}

Hours of flight were distributed in 4 periods: morning, afternoon, night, and early morning. The number of errors during each time of day, errors per $100 \mathrm{~h}$ flight time and normalized data by the Flight Operations Quality Assurance program are reported. The data have been normalized to the morning time of day (6:00 to 11:59). had reviewed level 3 events (errors), the data were forwarded for research. The analysis required the following data: total number of level 3 events (errors) in the month; times at which the events occurred (the FOQA system uses Zulu (Z) time); total number of events and the period of the day when they occurred; number of hours flown each month, supplied by the airline's statistics department.

Errors were distributed into four equal periods: morning (6:00-11:59), afternoon (12:00-17:59), night (18:00-23:59), and early morning (0:00-5:59).

Descriptive analysis was made with the aid of the Statistica version 5.1 program. The differences of risk during the day were reported as the ratio of morning to afternoon, morning to night and morning to early morning error rates.

\section{Results and Discussion}

As shown in Table 1, a total of 1065 level 3 errors were detected during the $155,327 \mathrm{~h}$ flown from April 1 to September 30,2005 , with the majority of the flights occurring during the morning. Clearly, the risk was increased by almost $50 \%$ during the early morning period compared to the morning. However, neither afternoon nor night was associated with greater risk.

The present study identified periods during the day in which a large sample of airline captains and copilots made errors more frequently. Human errors result from physiological and psychological limitations and causes include fatigue, workload, and fear as well as cognitive overload, poor interpersonal communications, imperfect information processing, and flawed decision making (4).

Night work requires the crew to perform tasks at a time when the organism should be resting instead of working. Almost daily stopovers for rest in places other than the home environment may be associated with increased fatigue, since external factors during resting periods, such as daylight, telephone, noises of elevators, traffic, and conversation interrupt sleep. Sleep becomes non-restorative and consequently leads to higher levels of fatigue and irritability, difficulty in concentration and perception, which may be contributory factors for the occurrence of errors. Note also that due to major alterations in sleep schedules, crew members can also present disrupted sleep patterns, such as sleep disorders $(2,5)$.

Operating long flights during the night (whether or not they are transmeridional) frequently conflicts with human circadian regulation and severely affects physiologic 
and psychological functions including in-flight performance. Body temperature drops most during the early morning, reaching its minimum at about 5:00 am (6), which suggests that this factor may affect crew member performance, due to the low level of physical and cognitive aspects during this period. However, we must emphasize that temperature by itself, cannot be regarded as a warning, which is influenced by other biological mechanisms. Thus, the biological rhythms reflect the contribution, to a greater or lesser degree, of endogenous components and masking effects (7).

Additional problems, such as sleep deprivation in the case of subjects staying awake to perform tasks or the effect of waking suddenly, directly affect performance. Goode (3) suggests that setting limits to hours worked by commercial pilots would reduce the risk of accidents caused by pilot fatigue.

A study conducted by Shappell et al. (8) included examinations of aviation accidents specific to the flight crew, environmental, supervisory, and organizational factors associated with two types of commercial aviation (air carrier and commuter/on-demand) accidents using the Human Factors Analysis and Classification System (HFACS). The study showed that the majority of accident causal factors were attributed to the flight crew and the environment, with decidedly fewer accidents associated with supervisory and organizational causes. Comparisons were made between HFACS causal categories and traditional situational variables such as visual conditions, injury severity, and regional (8).

The results of the present study suggested a relationship between time of day and higher levels of error during working time. Airlines should develop strategies for employees who work shifts or nights in order to minimize attention problems and fatigue in an attempt to help reduce errors.

\section{References}

1. Wright N, McGown A. Involuntary sleep during civil air operations: wrist activity and the prevention of sleep. Aviat Space Environ Med 2004; 75: 37-45.

2. Gander PH, Nguyen D, Rosekind MR, Connell LJ. Age, circadian rhythms, and sleep loss in flight crews. Aviat Space Environ Med 1993; 64: 189-195.

3. Goode $\mathrm{JH}$. Are pilots at risk of accidents due to fatigue? $J$ Safety Res 2003; 34: 309-313.

4. Helmreich RL, Merritt AC. Culture at work: national, organisational and professional influences. Aldershot: Ashgate; 1998.

5. Van Dongen HP. Shift work and inter-individual differences in sleep and sleepiness. Chronobiol Int 2006; 23: 1139-

1147.

6. Krauchi K, Wirz-Justice A. Circadian rhythm of heat production, heart rate, and skin and core temperature under unmasking conditions in men. Am J Physiol 1994; 267: R819R829.

7. Minors $D$, Waterhouse JM. The problem of masking and some ways to deal with it. In: Hilderbrandt G, Moog R, Raschke F (Editors), Chronibiology and chronomedicine. Frankfurt: Peter Lang; 1987. p 119-135.

8. Shappell S, Detwiler C, Holcomb K, Hackworth C, Boquet A, Wiegmann DA. Human error and commercial aviation accidents: an analysis using the human factors analysis and classification system. Hum Factors 2007; 49: 227-242. 